This item was submitted to Loughborough's Research Repository by the author.

Items in Figshare are protected by copyright, with all rights reserved, unless otherwise indicated.

\title{
Assessment of the occlusion technique as a means for evaluating the distraction potential of driver support systems
}

PLEASE CITE THE PUBLISHED VERSION

\section{PUBLISHER}

(C) Institution of Electrical Engineers

\section{LICENCE}

CC BY-NC-ND 4.0

\section{REPOSITORY RECORD}

Pettitt, Michael A., Gary E. Burnett, Steven H. Bayer, and Alan Stevens. 2019. "Assessment of the Occlusion Technique as a Means for Evaluating the Distraction Potential of Driver Support Systems". figshare. https://hdl.handle.net/2134/3017. 
This item was submitted to Loughborough's Institutional Repository by the author and is made available under the following Creative Commons Licence conditions.

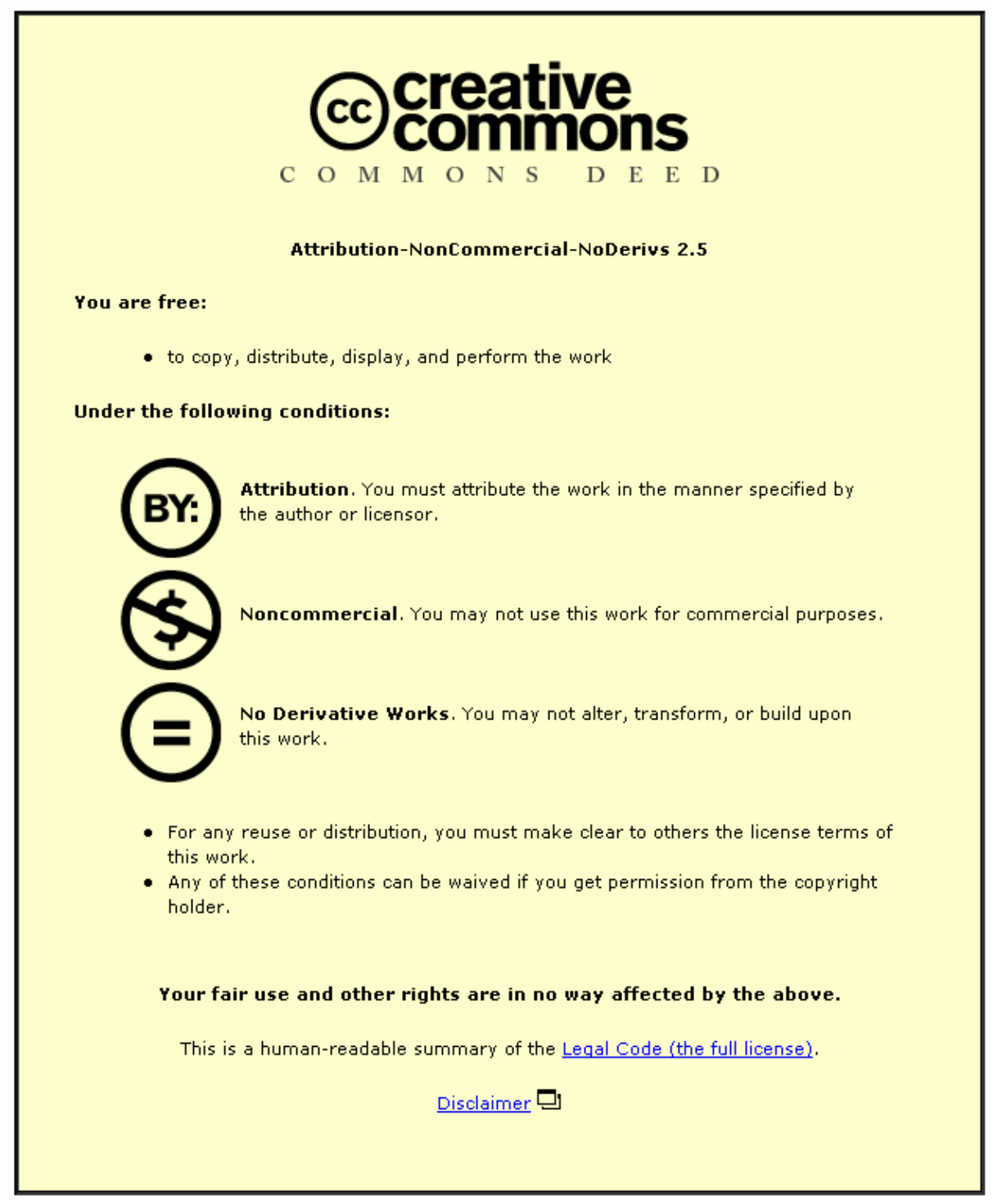

For the full text of this licence, please go to: http://creativecommons.org/licenses/by-nc-nd/2.5/ 


\title{
Assessment of the occlusion technique as a means for evaluating the distraction potential of driver support systems
}

\author{
MICHAEL A. PETTITT $\dagger^{*}$, GARY E. BURNETT $\dagger$, STEVEN BAYER $\$$ and ALAN \\ STEVENS§
}

$\uparrow$ School of Computer Science and Information Technology, University of Nottingham,

Nottingham, NG8 1BB, UK, email:map@cs.nott.ac.uk; geb@cs.nott.ac.uk

$\$$ Ergonomic and Safety Research Institute (ESRI), Loughborough University,

Loughborough, LE113UZ, UK, email: sbayer@lboro.ac.uk

$\S$ Transportation and Safety Division, TRL Ltd., Berkshire, RG40 3GA, UK, email:

\section{astevens@,trl.co.uk}

Driver distraction is a safety-critical issue that has been bought to greater public attention with the recent developments of more advanced driver support systems (DSS), such as navigation and collision warning. Tasks performed with such systems have the potential to distract drivers significantly from the primary task of controlling their vehicle, and this may result in an accident. Designers of DSS need to be able to assess this distraction potential in the early stages of design. In this respect, the occlusion technique and its associated measures are claimed to be reliable indicators of potential visual distraction. In particular, it has been argued that the technique provides more information concerning the likely visual demand of a system than other economical methods based on static task time, such as the 15-second rule. To investigate these assertions, a study compared results from an occlusion assessment and a road-based assessment. Sixteen experienced drivers carried out a range of tasks using two alternative user-interfaces under three conditions: statically, with full vision, statically, with restricted vision (occlusion), and whilst driving on a dual carriageway road within the UK. It was found that occlusion measures provided more information regarding the prospective visual demand of a DSS than did static task times. In particular, the resumability ratio assessed how far a task can be progressed whilst in periods with vision and without vision. It is concluded that the technique offers advantages over other methods, but requires a robust prototype for use as part of a driver-centred design process.

Keywords: Occlusion; Distraction; Driver Support Systems (DSS); Human

Computer Interaction (HCI); Methodology.

\footnotetext{
"Corresponding author. Tel: +44(0) 115951 4226, Fax: +44(0) 115951 4254, email: map@cs.nott.ac.uk
} 


\section{Introduction}

The task of driving is widely recognised (e.g. [1]) to comprise of three hierarchical levels: strategic (e.g. overall journey decisions); tactical (e.g. lane choices, route following); and control (e.g. braking, steering). Novel computing and communications technologies, such as navigation systems, adaptive cruise control and collision avoidance, aim to support drivers across all levels of the driving task, and hence improve the safety, efficiency and comfort/pleasure of the driving experience [2]. Such technologies are referred to within the literature using a wide range of terms (and their associated acronyms), at various levels of specificity, for example, Advanced Driver Assistance Systems (ADAS) [3], Transport Information and Control Systems (TICS) [4], and Advanced Traveller Information Systems (ATIS) [5]. In the context of this paper, the broad term, Driver Support Systems (DSS) [1] will be used.

Research investigating the design and evaluation of user-interfaces for DSS has not traditionally been a focus for human-computer interaction (HCI) specialists. Indeed, a cursory glance through HCI textbooks, journals and conferences reveals that there are remarkably few references to work in this area. In particular, it is noteworthy to see that a recent review of $102 \mathrm{HCI}$ papers concerning mobile devices [6] provides no mention of in-car systems. Instead, the bulk of literature concerning user-interface design within the driving context (more commonly referred to as Human-Machine Interface-HMI) is present within the Human Factors/Ergonomics, Traffic and Transport Psychology and more general Engineering sources.

An analysis of research concerning in-car user-interfaces (see for instance: [7], [8]) indicates there are three core questions that have been addressed: 
1. What are the impacts (in terms of safety, efficiency, comfort, etc.) of DSS on drivers, passengers, other road users, and for the traffic/transport system as a whole?

2. What is the potential for novel user-interfaces in a driving context, for example, speech recognition, head-up displays, gesture-driven interfaces, handwriting recognition, and so on?

3. What methods and measures are appropriate for use in the design and evaluation of DSS?

The current paper focuses on the latter question, and, in particular addresses the potential for the occlusion technique, a method which aims to provide a cost-effective means for assessing the visual demand of a DSS user-interface at early stages in the design process, as part of a driver-centred design approach.

\subsection{DSS and distraction}

Designers of DSS are faced with an atypical situation in user interface design, in that the interface being designed is 'secondary or peripheral to some performance-critical primary task' [9: 86]. As a consequence designers have a responsibility to consider not just the ease of interaction with the interface, but the effects that use of the interface may have on driving performance and behaviour [9]. The implications of a driver engaging in a secondary task that has adverse effects on driving performance are severe, and potentially fatal. Driver distraction is an established causal factor in road accidents 
[10], [11], [12]. It is felt that an increase in the number of cars equipped with DSS could potentially have an impact on the role distraction plays in automobile accidents (particularly if user-interfaces are poorly designed) [12], [13].

Driver distraction has been defined in a number of ways. In particular, it has been discussed in terms of four distinct types: visual, auditory, biomechanical, and cognitive distraction [14]. A distracting activity may comprise of a combination of these types [14]. Current DSS typically employ a range of complex displays and controls fitted within the vehicle, and, as such, are a potentially worrying source of visual distraction, defined as the 'diversion of visual attention from the road scene' [15: 10]. The user-interfaces for many DSS are 'largely based on the desktop computing paradigm and therefore require the user to engage in highly visually oriented tasks, such as scrolling and selecting items from lists, menu orientation, choosing individual characters from a large array, and so on' [8: 266].

The potential visual distraction afforded by a device is reliant on two factors: how visually demanding a DSS is when used, and driver motivation to engage with the device. Visual demand has been defined as the 'degree of visual activity required to extract information from an object to perform a specific task' [15: 10]. The motivation, or the 'willingness to engage', property of a system is difficult to measure as it relies on many factors that can be hard to quantify. For example, driver motivation may depend on: the driver's familiarity with the DSS; the importance of the secondary task to their overall goals at that particular moment in time; and, the wider driving environment, i.e. traffic, urban/rural location, day/night, and so on. As a consequence, predictive measures of visual distraction, such as the occlusion technique, instead tend to focus on the visual demand of a system. 
1.2 Predicting and measuring distraction through the occlusion technique

A human-centred design approach requires ways of understanding users' requirements and assessing the appropriateness of alternative user-interfaces, and, in this respect HCI offers a diversity of methods [16]. A driver-centred approach will make use of many of the same global techniques (for example, questionnaires, interviews, guidelines/checklists), but will, by necessity require its own methods (or at least specific versions of generic methods) that account for the particular complex, safety-critical characteristics of the driving context.

The occlusion technique has been investigated as a potentially useful measure of the visual demand associated with in-vehicle devices. Its premise lies in the assumption that, by allowing participants only brief periods of vision, the glance behaviour of performing a secondary task in the driving environment is simulated. In the driving environment visual attention is shared between the primary driving task and the secondary, in-vehicle task. With occlusion the periods where participants are without vision is representative of glances to the road scene. This behaviour is simulated by using a shutter or goggles to block and reveal the visual scene [17], [14]. If a task can be carried out effectively through a series of short glances it is felt that it is acceptable to perform whilst driving, as this is an indicator that a task is highly 'chunkable', and is easy to resume [17].

Interest in the occlusion technique has been driven by its low cost and ease of implementation when compared with more traditional measures of driver distraction, such as road and simulator studies [14], [17]. Whilst simulator and road studies require 
detailed planning (e.g. development/selection of appropriate road scenarios), timeconsuming analysis (e.g. eye-glance studies), and expensive equipment (e.g. driving simulators/instrumented vehicles), the occlusion technique can be implemented in a laboratory setting with the system under investigation only [17]. In addition, the technique can be used to evaluate several system properties, such as: 'chunkability, completion time, ease of resumption after interruption and visual complexity' [14: 36].

An international standard for the application of the occlusion technique is currently in the committee draft stage [15]. Whilst there is potential for various configurations of the technique, and a number of different measures can be made and reported, the standard seeks to provide a framework for research and the application of the method in order to improve comparability between studies.

In the standard, a number of conditions for study set up are given. The key points are as follows:

- A minimum of 10 participants should be used in any occlusion study;

- Participants should undergo training in tasks and the occlusion method;

- Up to 5 practice trials should be undertaken prior to actual trials;

- Participants should complete 5 trials on each task with full vision (static trials) and 5 trials whilst under occlusion conditions;

- Tasks acceptable for occlusion studies should have static task times of greater than 5 seconds;

- The order of occlusion and static trials should be counterbalanced to avoid learning effects; 
- In occlusion conditions, periods where participants are allowed vision are referred to as shutter open time. Periods where participants are without vision are referred to as shutter closed times (see Fig. 1 and Fig. 2).

\section{[INSERT FIGURE 1 ABOUT HERE]}

\section{[INSERT FIGURE 2 ABOUT HERE]}

There has been considerable debate within the research community regarding the length of time participants are allowed vision and the duration of occluded periods [17]. The draft standard proposes a shutter closed time of 2 seconds and a shutter open time of 1.5 seconds. 1.5 seconds is felt to be a tolerable time for drivers to glance away from the road whilst in motion [18], [19], [20].

The draft standard proposes that two measures should be reported following occlusion trials - the total shutter open time (TSOT), which is the total time that participants had vision whilst performing the task, and the resumability ratio $(\mathrm{R})$, which relates to the ease of resumption of a task following an interruption. The standard provides guidelines on the calculation of these two measures from the trials undertaken by each participant [15]. Guidelines include a rationale for the elimination of outliers. TSOT can either be recorded computationally, or calculated as follows:

$\mathrm{TSOT}=\left(\right.$ total task time occluded $\left._{\text {i }} / 3.5\right) * 1.5$

$\mathrm{R}$ is determined as the ratio of TSOT to total task time with full vision ( $\left.\mathrm{TTT}_{\text {static }}\right)$, such that: 
$\mathrm{R}=(\mathrm{TSOT}) /\left(\mathrm{TTT}_{\text {static }}\right)$

The values used in the calculation of $\mathrm{R}$ are taken from the mean TSOT and $\mathrm{TTT}_{\text {static }}$ values obtained from the five task instances undertaken by each participant.

1.3 Validity of the occlusion technique

A number of studies have sought to assess the validity of the occlusion technique [14], [17]. Whilst individual research has demonstrated that the technique has promise, there is concern that there has been a lack of coordination between studies [14]. Correlations have been found between occlusion measures and a number of measures of driving performance, implying that occlusion trials may be a valid substitute for on-road and simulator studies [17]. As the draft ISO standard requires that only the TSOT and the R ratio be reported, this section will focus on the validity of those measures.

Studies have shown TSOT to correlate highly with total glance time - the total time drivers spend glancing away from the road whilst driving [21], [22]. As TSOT is much more easily obtained than total glance time, this is very encouraging [17]. Recommendations regarding acceptable values for TSOT have been made; however, research suggests that many DSS seriously exceed these [17]. Total glance time has also been shown to correlate well with static task time with full vision [23].

Research has also suggested a strong correlation between total glance time and lane deviations, a driving safety measure [24], [22]. However, it is argued that there are problems with assessing DSS based on total glance time; high values imply the DSS is 
unsafe, yet if a task is highly chunkable, requiring only short glances, this may not be the case [17]. It is suggested that measures of static task time alone are not enough, as they fail to discriminate between tasks that require long glances and those that can be completed with only short glances [14], [17]. Similar issues have been raised regarding total glance time. In an on-road study, Chiang et al. [25] reported average total glance times of 34.1 seconds whilst performing a destination entry task. The authors found that participants made a similar number of lane exceedences when performing the secondary task as in a baseline condition (driving only, with no secondary task to perform). This was attributed to the highly interruptible nature of the task. Thus, a task may have a high total glance time value but this may be acceptable if individual glances are short. A task with a total glance time of 34 seconds comprised of 34 individual, one second glances, is more desirable than a task with a total glance time of 17 seconds comprised of, for example, three long glances. As TSOT correlates well with total glance time it can be inferred that the measure may have similar failings. Therefore, it is proposed that static task time, TSOT and total glance time are not necessarily indicative of the impact of a task on driving performance [17].

The occlusion technique seeks to address the shortcomings of measuring TSOT with a further measure: the resumability ratio $(\mathrm{R})$. The $\mathrm{R}$ ratio is used to evaluate 'the degree to which a task can be done without visual control' [17: 25]. Care should be taken with the measure as it can be negatively affected by the static task time. The draft ISO standard suggests that the occlusion technique is only suitable for tasks longer than 5 seconds in duration. $\mathrm{R}$ has been found to be influenced more by static task time when static task time is short, than by task complexity [26], [27]. 
The majority of studies in this area have aimed to validate the occlusion technique using data from simulator trials. Few, in contrast, have compared occlusion results with on-road studies (a notable exception is [28]). By measuring driving performance variables in a real vehicle, driving on public roads, participants' behaviour will inevitably be more naturalistic than when the same tasks are performed in a simulator. Questions have been raised over the validity of driving simulators, that is, whether drivers behave in the simulator as they would on the road [29].

Furthermore, there is a lack of research that aims to validate occlusion in its intended role, that is, as a design tool enabling a researcher/developer to make design decisions regarding alternative user-interfaces. Put simply, if the user-interface for one system is favoured over another in occlusion trials, is the same true of data gathered from road trials? In addition, does occlusion provide any more significant information than simply measuring total task time when stationary? These questions are the basis for a road-based evaluation study comparing a destination entry task and a sound manipulation task on two DSS under the following conditions: statically with vision; statically, with restricted vision (occlusion); and, driving on a dual carriageway. The full method and results are discussed below.

\section{Method}

\subsection{Participants}

Sixteen licensed drivers took part in the trials. The mean age was $41.2, \mathrm{SD}=19.8$, range 22 to 68 . There was an even split between genders. Driving experience was noted by 
annual mileage (see table 1 for a summary). Participants had held full driving licenses for an average of 22 years ( $S D=19$, range: 5 to 54$)$. Participants were paid for their time.

Table 1: driving experience of participants

\begin{tabular}{cc}
\hline Annual Mileage & Participants \\
\hline 0 to 1000 & 1 \\
\hline 1001 to 5000 & 3 \\
\hline 5001 to 10000 & 7 \\
\hline 10001 to 15000 & 2 \\
\hline 15001 to 20000 & 2 \\
\hline $20000+$ & 1 \\
\hline
\end{tabular}

\subsection{Equipment}

The trials were conducted in a Honda Civic. Static trials and occlusion trials were performed in the stationary vehicle. The road trials took place on a section of the A50 in Leicestershire/Derbyshire, United Kingdom; a two-lane dual carriageway restricted by the national speed limit of $70 \mathrm{mph}$. Participants were instructed to try and maintain a speed of $70 \mathrm{mph}$ throughout the trial, traffic permitting. Two systems were assessed in the study. System A incorporated a commercially available, integrated navigation system / entertainment system with the vehicle's original heating, ventilation and airconditioning (HVAC) controls. System B was a prototype system, which combined navigation, in-vehicle entertainment and HVAC controls. The trial car was equipped with four cameras to record: the driver's face; the road scene ahead; the system controls and display; and, the overall driver cockpit environment (see Fig. 3). In the occlusion trials, PLATO (portable liquid-crystal apparatus for tachistoscopic occlusion) goggles 
were used as a means of achieving occlusion [30]. These goggles are commonly used as a means of achieving occlusion [17]. A laptop computer is used to determine the translucency/transparency of the goggle lenses at the regular intervals required by the draft standard [15].

[INSERT FIGURE 3 ABOUT HERE]

2.3 Tasks

Two tasks were selected for the trials based on the comparability between systems and their suitability for occlusion. In particular, the draft ISO standard requires that tasks assessed by the occlusion technique have static task times of greater than 5 seconds. The first task involved the navigation function of each system, and required participants to select a destination from a stored list and confirm it. The second task involved manipulation of the sound characteristics within the vehicle, such as adjusting the levels for treble, bass, balance and fade. Both tasks could be satisfactorily completed on each system and were in excess of the 5 seconds stationary task time necessary to be eligible for occlusion.

\subsection{Trial setup and process}

Prior to the occlusion and road trials, participants were made familiar with the car and its controls and fully trained in the use of the system. In a repeated measures design, each participant completed two trials, one for each system, with a delay of around 2 to 4 
weeks between trials. This was felt to minimise any learning effects regarding trial procedure. To avoid order effects, half of the participants completed the trials with the order System A - System B, whilst the other half followed the order System B - System A.

The occlusion trials were conducted whilst sat in the vehicle, which was stationary. The procedure for the occlusion trials followed that given in the most up-todate version of the draft standard available at the time of the trials [31]. Participants were trained in the tasks and given five practice trials in order to familiarise themselves with the task/system. An assessment was made of their ability to perform the tasks to a satisfactory level before the full occlusion trial. Five task instances were undertaken with full vision and five under occlusion conditions, as per the draft standard. Ordering of static versus occluded trials was counterbalanced to minimise learning effects.

In the road trial, participants drove a 20 -minute route twice whilst performing several tasks, including the two examined using occlusion. Video data was analysed on the second trip, in order to ensure participants were fully competent in the tasks.

\section{Results}

A number of technical issues were encountered during the trials that reduced the initial dataset of 16 participants. The quantity of participant data under each condition is detailed in table 2. 
Table 2: number of participant data for each condition

\begin{tabular}{ccc|cc|cc}
\hline & \multicolumn{2}{c|}{ Static task time } & \multicolumn{2}{c|}{ Occlusion measures } & \multicolumn{2}{c}{ Road trial measures } \\
\hline & $\begin{array}{c}\text { Navigation } \\
\text { Task }\end{array}$ & $\begin{array}{c}\text { Sound } \\
\text { Task }\end{array}$ & Navigation & Sound & Navigation & Sound \\
Task & Task & Task & Task \\
\hline System A & 14 & 15 & 15 & 15 & 13 & 14 \\
\hline System B & 14 & 15 & 12 & 11 & 14 & 14 \\
\hline
\end{tabular}

Comparisons were made between the following measures:

1. Static task time

2. TSOT

3. $\mathrm{R}$

4. Total Glance Time

5. Glance frequency

6. Total on-road task time

7. Proportion of on-road task time spent with eyes off the road

8. Average glance duration

Measures 1, 2 and 3 were all obtained during the occlusion trials following the procedure outlined in the draft occlusion standard [15]. Measures 4, 5, 6, 7 and 8 were all obtained from the road trials based on video analysis. Measures were selected by requirement (e.g. the occlusion measures) and based on measures used in previous research (see section 1.3). The results were analysed between systems for each task i.e. is System A better/worse than System B? - and between tasks on each system - i.e. on System A, is task 1 better/worse than task 2? Two sample t-tests were conducted to assess differences in values. 
3.1 Results between systems for navigation task

The navigation task on each system required participants to access a stored list of destinations, select a specified destination and finally, confirm it as their choice. The results are summarised in table 3. For this task, no significant differences were found between either system in any of the conditions, leading to the conclusion that neither system is more or less acceptable than the other. As no significant differences were found, it is not possible to draw any firm conclusions regarding the validity of the occlusion technique at this stage. However, it can be noted that the results from the occlusion study are in keeping with the outcome of the static task time results and those from the road study.

Table 3: Comparison of results for System A and System B for Navigation task showing means and standard deviations (in brackets)

\begin{tabular}{|c|c|c|c|c|c|c|c|c|}
\hline & \multicolumn{3}{|c|}{ Occlusion } & \multicolumn{5}{|c|}{ On-road } \\
\hline & $\begin{array}{l}\text { Static } \\
\text { task } \\
\text { time }\end{array}$ & $\begin{array}{l}\text { Total } \\
\text { Shutter } \\
\text { Open } \\
\text { Time }\end{array}$ & $\begin{array}{l}\text { Resumability } \\
\text { Ratio }\end{array}$ & $\begin{array}{l}\text { Dynamic } \\
\text { Task } \\
\text { Time }\end{array}$ & $\begin{array}{l}\text { Total } \\
\text { Glance } \\
\text { Time }\end{array}$ & $\begin{array}{l}\% \text { task } \\
\text { time } \\
\text { 'eyes } \\
\text { off } \\
\text { road' }\end{array}$ & $\begin{array}{l}\text { Glance } \\
\text { Frequency }\end{array}$ & $\begin{array}{l}\text { Single } \\
\text { Glance } \\
\text { Time }\end{array}$ \\
\hline $\begin{array}{l}\text { System } \\
\text { A }\end{array}$ & $\begin{array}{l}11.0 \\
(4.36)\end{array}$ & $\begin{array}{l}9.3 \\
(2.75)\end{array}$ & $\begin{array}{l}0.94 \\
(0.33)\end{array}$ & $\begin{array}{l}21.4 \\
(10.37)\end{array}$ & $\begin{array}{l}12.7 \\
(5.90)\end{array}$ & $61.8 \%$ & $\begin{array}{l}11.5 \\
(3.91)\end{array}$ & $\begin{array}{l}1.08 \\
(0.20)\end{array}$ \\
\hline $\begin{array}{l}\text { System } \\
\text { B }\end{array}$ & $\begin{array}{l}11.4 \\
(3.11)\end{array}$ & $\begin{array}{l}9.4 \\
(1.78)\end{array}$ & $\begin{array}{l}0.84 \\
(0.20)\end{array}$ & $\begin{array}{l}22.0 \\
(8.97)\end{array}$ & $\begin{array}{l}12.9 \\
(5.26)\end{array}$ & $60.7 \%$ & $\begin{array}{l}11.1 \\
(3.93)\end{array}$ & $\begin{array}{l}1.17 \\
(0.24)\end{array}$ \\
\hline $\begin{array}{l}\text { Design } \\
\text { decision }\end{array}$ & Neither & Neither & Neither & Neither & Neither & Neither & Neither & Neither \\
\hline
\end{tabular}




\subsection{Results between systems for sound settings task}

The sound task required participants to manipulate sound settings such as the treble, bass, balance and fade levels. The results are summarised in table 4. For this task significant differences were found between the systems in all but one measure, mean single glance time. The majority of the measures favour System A, however two measures - the $\mathrm{R}$ ratio $(\mathrm{t}(24)=3.08 ; \mathrm{p}<0.01)$ and the proportion of task time spent with eyes off the road $(\mathrm{t}(26)=2.17 ; \mathrm{p}<0.05)-$ favour System B.

Table 4: Comparison of results for System and System B for Sound task showing means and standard deviations (in brackets). Shaded areas indicate a significant difference in favour of the corresponding system.

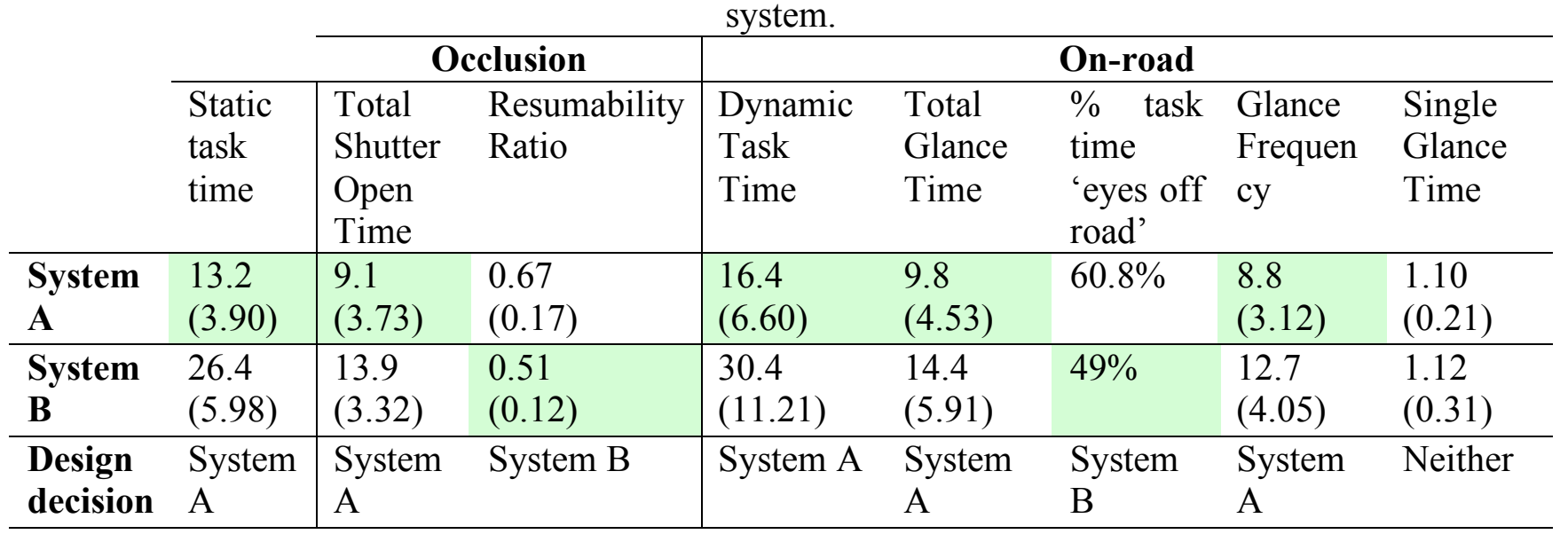

\subsection{Results between tasks for System A}

Table 5 compares the results for each task on System A, and provides a decision on which task is most suitable for use whilst driving based on each measure. Although almost all measures suggest there is no significant difference between the two tasks on this system, the $\mathrm{R}$ ratio indicates a preference for the sound task $(\mathrm{t}(21)=2.61 ; \mathrm{p}<0.05)$, and this is replicated in the glance frequency $(\mathrm{t}(23)=2.01 ; \mathrm{p}<0.05)$. 
Table 5: comparison between tasks for System A showing means and standard deviations (in brackets). Shaded areas indicate a significant difference in favour of corresponding task.

\begin{tabular}{|c|c|c|c|c|c|c|c|c|}
\hline & \multicolumn{3}{|c|}{ Occlusion } & \multicolumn{5}{|c|}{ On-road } \\
\hline & $\begin{array}{l}\text { Static } \\
\text { task } \\
\text { time }\end{array}$ & $\begin{array}{l}\text { Total } \\
\text { Shutter } \\
\text { Open } \\
\text { Time }\end{array}$ & $\begin{array}{l}\text { Resumability } \\
\text { Ratio }\end{array}$ & $\begin{array}{l}\text { Dynamic } \\
\text { Task } \\
\text { Time }\end{array}$ & $\begin{array}{l}\text { Total } \\
\text { Glance } \\
\text { Time }\end{array}$ & $\begin{array}{l}\% \text { task } \\
\text { time } \\
\text { 'eyes off } \\
\text { road' }\end{array}$ & $\begin{array}{l}\text { Glance } \\
\text { Frequen } \\
\text { cy }\end{array}$ & $\begin{array}{l}\text { Single } \\
\text { Glance } \\
\text { Time }\end{array}$ \\
\hline $\begin{array}{l}\text { Nav } \\
\text { task }\end{array}$ & $\begin{array}{l}11.0 \\
(4.36)\end{array}$ & $\begin{array}{l}9.3 \\
(2.75)\end{array}$ & $\begin{array}{l}0.94 \\
(0.33)\end{array}$ & $\begin{array}{l}21.4 \\
(10.37)\end{array}$ & $\begin{array}{l}12.7 \\
(5.90)\end{array}$ & $61.8 \%$ & $\begin{array}{l}11.5 \\
(3.91)\end{array}$ & $\begin{array}{l}1.08 \\
(0.20)\end{array}$ \\
\hline $\begin{array}{l}\text { Sound } \\
\text { task }\end{array}$ & $\begin{array}{l}13.2 \\
(3.90)\end{array}$ & $\begin{array}{l}9.1 \\
(3.73)\end{array}$ & $\begin{array}{l}0.67 \\
(0.17)\end{array}$ & $\begin{array}{l}16.4 \\
(6.60)\end{array}$ & $\begin{array}{l}9.8 \\
(4.53)\end{array}$ & $60.8 \%$ & $\begin{array}{l}8.8 \\
(3.12)\end{array}$ & $\begin{array}{l}1.10 \\
(0.21)\end{array}$ \\
\hline $\begin{array}{l}\text { Design } \\
\text { decision }\end{array}$ & Neither & Neither & Sound task & Neither & Neither & $\begin{array}{l}\text { Sound } \\
\text { task }\end{array}$ & $\begin{array}{l}\text { Sound } \\
\text { task }\end{array}$ & Neither \\
\hline
\end{tabular}

3.4 Results between tasks for System B

Table 6 compares results for each task on System B, similar to the table in the previous section.

Table 6: Comparison between tasks for System B showing means and standard deviations (in brackets). Shaded areas indicate a significant difference in favour of corresponding task.

\begin{tabular}{|c|c|c|c|c|c|c|c|c|}
\hline & & \multicolumn{2}{|c|}{ Occlusion } & \multicolumn{5}{|c|}{ On-road } \\
\hline & $\begin{array}{l}\text { Static } \\
\text { task } \\
\text { time }\end{array}$ & $\begin{array}{l}\text { Total } \\
\text { Shutter } \\
\text { Open } \\
\text { Time }\end{array}$ & $\begin{array}{l}\text { Resumability } \\
\text { Ratio }\end{array}$ & $\begin{array}{l}\text { Dynamic } \\
\text { Task } \\
\text { Time }\end{array}$ & $\begin{array}{l}\text { Total } \\
\text { Glance } \\
\text { Time }\end{array}$ & $\begin{array}{l}\% \text { task } \\
\text { time } \\
\text { 'eyes off } \\
\text { road' }\end{array}$ & $\begin{array}{l}\text { Glance } \\
\text { Frequen } \\
\text { cy }\end{array}$ & $\begin{array}{l}\text { Single } \\
\text { Glance } \\
\text { Time }\end{array}$ \\
\hline $\begin{array}{l}\text { Nav } \\
\text { task }\end{array}$ & $\begin{array}{l}11.4 \\
(3.11)\end{array}$ & $\begin{array}{l}9.4 \\
(1.78)\end{array}$ & $\begin{array}{l}0.84 \\
(0.20)\end{array}$ & $\begin{array}{l}22.0 \\
(8.97)\end{array}$ & $\begin{array}{l}12.9 \\
(5.26)\end{array}$ & $60.7 \%$ & $\begin{array}{l}11.1 \\
(3.93)\end{array}$ & $\begin{array}{l}1.17 \\
(0.24)\end{array}$ \\
\hline $\begin{array}{l}\text { Sound } \\
\text { task }\end{array}$ & $\begin{array}{l}26.4 \\
(5.98)\end{array}$ & $\begin{array}{l}13.9 \\
(3.32)\end{array}$ & $\begin{array}{l}0.51 \\
(0.12)\end{array}$ & $\begin{array}{l}30.4 \\
(11.21)\end{array}$ & $\begin{array}{l}14.4 \\
(5.91)\end{array}$ & $49 \%$ & $\begin{array}{l}12.7 \\
(4.05)\end{array}$ & $\begin{array}{l}1.12 \\
(0.31)\end{array}$ \\
\hline $\begin{array}{l}\text { Design } \\
\text { decision }\end{array}$ & $\begin{array}{l}\text { Nav } \\
\text { task }\end{array}$ & $\begin{array}{l}\text { Nav } \\
\text { task }\end{array}$ & Sound task & Nav task & Neither & Nav task & Neither & Neither \\
\hline
\end{tabular}

There was no significant difference discovered between the tasks for three measures: total glance time, glance frequency, and single glance time. Three measures showed a preference for the navigation task: static task time $(\mathrm{t}(20)=-8.35 ; \mathrm{p}<0.001)$; $\operatorname{TSOT}(\mathrm{t}(15)$ $=-3.97 ; \mathrm{p}<0.005)$; on-road task time $(\mathrm{t}(25)=-2.19 ; \mathrm{p}<0.005)$. Two measures showed a 
significant difference in favour of the sound task: $\mathrm{R}(\mathrm{t}(18)=4.83 ; \mathrm{p}<0.0005)$ and the proportion of task time with eyes off the road $(\mathrm{t}(26)=2.05 ; \mathrm{p}<0.05)$.

\section{Discussion}

4.1 The validity of the technique

The occlusion technique aims to provide designers of DSS with unique information about the visual demand of a particular task/system. It is suggested that measures of static task time alone are not enough, as they fail to discriminate between tasks that require long glances and those that can be completed with only short glances [14], [17]. From the results of this study it is apparent that the occlusion technique does provide more useful information about design features than static measures, in particular with the measure known as the resumability ratio (R). Contrary to expectations, in the results reported, the $\mathrm{R}$ ratio did not relate to any difference in single glance durations. Instead the measure was found to be sensitive to the proportion of a task that could be completed non-visually (section 4.3 discusses the implication of this finding in more detail).

Key to the occlusion technique's success in assessing potential visual demand is the ease of implementation. There are few techniques that can inform designers early enough in the design process so that changes can be effectively made to designs. It is possible that the occlusion technique can be implemented slightly earlier than assessments that rely on simulator or road trials; however, the technique does require a usable prototype, and therefore is still only really applicable to later stages of design. 
Despite this, the occlusion technique still has its advantages. It is likely to be less expensive than simulator or road studies and the analysis is much more efficient. The draft ISO standard suggests that the technique can be used in a variety of locations, including in a laboratory [15]. Therefore a prototype need only require working controls and display. This differs in particular to road trials, where the physical constraints of the vehicle place restrictions on prototype systems. Stevens et al. [17] suggest that there are advantages and disadvantages to conducting occlusion trials in laboratory settings. Although cheaper to run, participants are not performing tasks in their intended locations, i.e. in a vehicle. No studies, at the time of writing, have compared results obtained in a laboratory with those from a vehicle.

\subsection{Total Shutter Open Time (TSOT)}

Although significant differences were found in TSOT values in two cases, the preferred task/system was the same as suggested by the static task time value. No differences were found in static task time values that weren't replicated in the TSOT values. TSOT can still be viewed as a useful measure; however, on its own it does not appear to provide enough new information to make the occlusion technique worthwhile. As was discussed earlier, TSOT has been shown to correlate strongly with total glance time. However, there are doubts regarding this measure's relation to driving performance [17].

4.3 Resumability ratio $(\mathrm{R})$ 
In three of the above cases the $\mathrm{R}$ ratio is inconsistent with the majority of other measures. For the results between systems on the sound task (Table 4) and the results between tasks for System B (Table 6), the $\mathrm{R}$ ratio shows a significant difference in favour of the opposite task/system to the TSOT. For the results between tasks on System A (Table 5), there is a significant difference between the $\mathrm{R}$ values but no significant difference for the TSOT. This suggests that the value of $\mathrm{R}$ is potentially the most useful piece of information provided by the occlusion technique, providing designers/researchers with some more detail than static task time measures alone.

Higher values of $\mathrm{R}$ are said to indicate that participants have difficulty completing the task in the brief periods of vision available during occlusion trials [15]. The logical conclusion to draw is that a system or task with a higher $\mathrm{R}$ ratio will result in participants making longer glances whilst driving in order to complete the task. However, it has been suggested that drivers will generally self-regulate their glance behaviour, and will only tolerate glances of up to 1.5 seconds duration. After this, attention will be returned to the forward view regardless of whether or not a goal has been achieved [18]. In this study, despite significant differences between values of $\mathrm{R}$, no significant differences were detected between the values for single glance duration in road trials. In all cases, average single glance duration is just above 1 second. This supports Wierwille's [18] assertion that glances should ideally be no more than a second, but longer glances of up to 1.5 seconds will be tolerated when information can be gathered in that time.

Although no effect was found on single glance durations, in two cases a significant difference was found in the proportion of task time spent with eyes off the road, consistent with the difference found in the values of $\mathrm{R}$. This suggests that in both 
the occlusion trial and the road trial, participants were capable of completing large parts of a task without vision. That is, in the occlusion trial participants were able to further their progress in a task significantly during the periods where vision was occluded. In the case of the sound task on System B, this is highly logical. The task was long in duration, as it required multiple button presses. Many of these button presses were repetitive in nature, and, as such, participants were able to comfortably continue the task whilst their vision was occluded, in the occlusion trials, or whilst looking at the road ahead, in the road trial. For the equivalent task on System A, participants were less aware of the mode the system was in without looking to the display. In addition, System A had a time out feature that returned the display to the main menu after a short period of inactivity. This may have resulted in more glances being made for reference purposes than for the equivalent task on System B.

The results emphasise that $\mathrm{R}$ is dependent on two factors of a system. Namely, how much of a task can be completed in brief periods of vision and how much can be done whilst deprived of vision. A low R ratio does not necessarily imply shorter glance durations as opposed to a higher value, but may suggest that large quantities of a task can be completed whilst not looking to the system. In section 1.1, it was suggested that visual distraction is influenced by two properties of a DSS: visual demand and the driver's motivation to use the system. The two occlusion measures, TSOT and R, are felt to be reliable measures of the visual demand of a DSS.

\subsection{Road trial issues}


On-road studies are viewed as highly effective and accurate ways of measuring distraction, providing the opportunity to assess DSS in real world driving conditions [14]. However, such studies are infrequently conducted for several reasons: they are costly to run and time consuming; real-world traffic and environmental conditions are unpredictable; and there are ethical considerations when asking participants to engage in tasks that may be potentially unsafe [14]. The analysis of road trial results can also be time consuming. For this study, video data was captured that required frame-by-frame analysis in order to record glance data. Without expensive analysis tools, video data analysis can be very resource intensive [14].

\subsection{Prototype issues}

A number of technical difficulties were encountered with the prototype System B throughout the course of the trials. Issues included the build quality of the prototype and problems with the prototype software. Careful planning of task orders was necessary in order to minimise the effects of software problems and participants were asked to be reasonably gentle in their handling of the prototype to avoid build quality issues. The prototype was not fully functional, although it was possible to complete all tasks in a meaningful way. Green [32] states that when evaluative methods require fully functional systems, any problems with the system are identified too close to production to make changes to the design. This is a major drawback to road-trial and simulator evaluation studies. It is the experience of this study that there are similar drawbacks to the occlusion technique. However, given the ease of application of the technique and the 
efficiency of the data analysis, it could potentially be used to assess existing system designs in order to help formulate guidelines and standards for good design.

\section{Conclusions}

This paper details a study aimed at assessing the validity of the occlusion technique to measure visual distraction through comparison of results between two systems and an on-road evaluation. The key questions were:

1. Do results from occlusion trials indicate a similar preference for a system to results gathered in an on-road study?

2. Does occlusion provide any more information than measures of static task time alone?

The results indicate that occlusion is a valid tool for the assessment of potential visual demand of a system. Trends predicted by occlusion were mirrored in the results from the on-road study. It was demonstrated that the technique provided more information than measurements of static task time alone through the $\mathrm{R}$ ratio. In addition, it was felt that the technique was much more efficient to run in practice than road trials. The analysis of data for occlusion is also far less time consuming.

It was felt that clarification might be necessary regarding the information provided by $\mathrm{R}$. This measure was found to be not necessarily indicative of average glance durations. The $\mathrm{R}$ ratio is reliant on two factors: the amount of information that can be obtained during periods of vision and the amount of a task that can be completed without vision. A low $\mathrm{R}$ ratio, therefore, does not necessarily mean shorter glance 
durations, but can suggest that large portions of the task can be completed without vision. This finding does not suggest the $\mathrm{R}$ ratio is any less important, as it still relates to the visual demand of a system; however, it should be considered when applying the technique.

As yet, there are no acceptable (or limiting) values for the measures TSOT and R. Research should address this issue. Potential studies could examine whether acceptable values could be variable: that is, a higher TSOT may be acceptable when $\mathrm{R}$ is below an agreed level. Similarly, a greater R ratio may be acceptable when TSOT is small. If the occlusion technique is to be used in the practical development of new DSS, this issue needs to be addressed.

Of the two systems assessed in this study, one was a prototype, which presented many problems throughout the course of the study. The occlusion technique is built around user trials, and therefore requires either a very advanced prototype or fully working model for trials to be successful. Given the difficulties experienced in this study, doubt is cast over the application of the technique in earlier stages of design. However, the technique could be used to assess existing DSS with a view to forming standards and guidelines.

\section{Acknowledgements}

The authors would like to acknowledge the following people for their assistance in this study: John Richardson and Terry Harrison at ESRI for their assistance in the setup and running of the road trials; Mark Porter and Steve Summerskill in the Department of Design of Technology, Loughborough University, for the development of the prototype 
system; and, Katharine Prynne at Honda R\&D Europe Ltd, for the provision of the instrumented vehicle.

\section{References}

[1] Michon, J.A. (Ed.), 1993, Generic Intelligent Driver Support: A Comprehensive Report on the GIDS Project (London: Taylor \& Francis).

[2] BISHOP, R., 2005, Intelligent Vehicle Technology and Trends (London: Artech House Books).

[3] Zwaneveld, P.J., van Arem, B., Bastiaensen, E.G.H.J., Soeteman, J.J., Frémont, G., BÉlarbi, F., Ulmer, B., Bonnet, C., \& Gölliger, H., 1999, Deployment scenarios for advanced driver assistance systems, Report Intro/VK 199907, TNO Inro, Delft, The Netherlands.

[4] PARKES, A., 1997, The role of Standards for In-Vehicle MMI. In Ergonomics and Safety of Intelligent Driver Interfaces, Y.I. Noy (Ed.), (New Jersey: Lawrence Erlbaum Associates), pp. $393-409$.

[5] Mollenhauer, M.A., Hulse, M.C., Dingus, T.A., Jahns, S.K., Carney, C., 1997, Design Decision Aids and Human Factors Guidelines for ATIS Displays. In Ergonomics and Safety of Intelligent Driver Interfaces, Y.I. Noy (Ed.) (New Jersey: Lawrence Erlbaum Associates), pp. 23 - 61.

[6] KJeldskov, J., \& Graham, C., 2003, A Review of Mobile HCI Research Methods. Lecture Notes in Computer Science (vol 2795/2003) (Springer-Verlag GmbH), pp. 317335.

[7] Noy, Y.I. (Ed.), 1997, Ergonomics and Safety of Intelligent Driver Interfaces, (New Jersey: Lawrence Erlbaum Associates). 
[8] Burnett, G.E., Summerskill, S.J., \& Porter, J.M., 2004, On-the-move destination entry for vehicle navigation systems: Unsafe by any means? Behaviour and Information Technology, 23(4), 265-272

[9] SAlvUCCI, D. D., 2001, Predicting the effects of in-car interface use on driver performance: an integrated model approach. International Journal of Human-Computer Studies 55: 85-107.

[10] Wang, J., KNiPling, R. R., \& Goodman, M. J., 1996, The role of driver inattention in crashes: new statistics from the 1995 crashworthiness data system, $40^{\text {th }}$ annual proceedings for the advancement of automotive medicine, Vancouver, British Columbia, pp. 377-392.

[11] GreEn, P., 2000, Crashes induced by driver information systems and what can be done to reduce them. SAE paper 2000-01-C008.

[12] Stevens, A., Minton, R., 2001, In-vehicle distraction and fatal accidents in England and Wales, Accident Analysis and Prevention 33: 539-545.

[13] Dewar, R.E., 2002, Vehicle Design. In Human Factors in Traffic Safety, Dewar, R.E. \& Olson, P.L. (Eds.) (USA: Lawyers \& Judges Publishing Company, Inc.), pp. 303-339.

[14] Young, K., Regan, M., \& HAMmer, M., 2003, Driver distraction: a review of the literature, Monash University Accident Research Centre, Report No. 206, November 2003.

[15] ISO, 2005, Road vehicles - Ergonomic aspects of transport information and control systems - Occlusion method to assess visual distraction due to the use of in-vehicle information and communication systems. Draft International Standard ISO/DIS 16673. ISO/TC 22/SC 13. 
[16] DiX, A., Finlay, J., Abowd, G.D., Beale, R. (Eds.), 2003, Human Computer Interaction ( $3^{\text {rd }}$ Edition) (London: Pearson Prentice Hall).

[17] Stevens, A., Bygrave, S., Brook-Carter, N., Luke, T., 2004, Occlusion as a technique for measuring in-vehicle information system (IVIS) visual distraction: a research literature review. Transport Research Laboratory (TRL) report no. TRL609. TRL, Crowthorne, Berkshire, United Kingdom.

[18] WIERWILLE, W. W., 1993, An initial model of visual sampling of in-car displays and controls. In Vision in Vehicles IV, A.G.Gale (Ed.), (North Holland: Elsevier Science Publishers B.V.), pp. 271-280.

[19] Weir, D. H., Chiang, D. P., \& Brooks, A. M., 2003, A study of the effect of varying visual occlusion and false duration conditions on the driver behaviour and performance or using secondary task human-machine interface. ADE technical papers series 2003-01-0128. 2003 SAE world congress, Detroit, Michigan, March 3-6, 2003. [20] RocKWELL, T. H., 1988, Spare visual capacity in driving-revisited: new empirical results for an old idea. In Vision in Vehicles II, A.G. Gale et al (Eds.), (Amsterdam: Elsevier), pp. 317-324.

[21] NIIYA, K., 2000, Trial evaluation results on navigation operation using occlusion technique. Discussion paper: ISO/TC22/SC13/WG8 Visual distraction TF. Toyota Motor Corporation. November 13, 2000. ISO/TC22/SC13/WG8/N289.

[22] Hashimoto, K. \& Atsumi, B., 2001, Study of occlusion technique for making the static evaluation method of visual distraction, Evaluation Method of Visual Distraction, 2000 ITS World Congress, November 15, 2001.

[23] GreEn, P., 1999, The 15 second rule for driver information systems. Proceedings of the ITS America ninth annual meeting, Washington, D.C. 
[24] Curry, R., Greenberg, J. And Blanco, M., 2002, An alternate method to evaluate driver distraction. Intelligent Transport Society of America's Twelfth Annual meeting and Exposition. April $29^{\text {th }}$-May $2^{\text {nd }}, 2002$.

[25] Chiang, D.P., Brooks, A.M., \& WeIR, D. H., 2001, An experimental study of destination entry with an example automobile navigation system. (SAE paper 2001-010810), in Intelligent Vehicle Initiative (IVI): Technology and Navigation Systems, (Warrendale, PA: Society of Automative Engineers), pp. 113-123.

[26] GoujOn, S., 2001, First evaluation of possible occlusion technique criteria. LAB PSA, Peugeot-Citroen/Renault, Workshop on Occlusion, Torino, Italy, $12-13^{\text {th }}$ November 2001.

[27] KARLSSON, R. \& FichtenBERG, N, 2001, How different occlusion intervals affect total shutter open time. Written by Volvo Car Corporation in August 2001. Workshop on Occlusion, Torino, Italy, 12-13 ${ }^{\text {th }}$ November 2001.

[28] Baumann, M., Keinath, A., Krems, J.F., And Bengler, K, 2004, Evaluation of in-vehicle HMI using occlusion techniques: experimental results and practical implications. Applied Ergonomics 35(3): 197-205.

[29] ReED, M.P., GREEN, P.A., 1999, Comparison of driving performance on-road and in a low-cost simulator using a concurrent telephone dialling task. Ergonomics 42(8): $1015-1037$.

[30] TRANSLuCENT TECHNOLOGIES, 2005, http://home.ca.inter.net/ milgram/.

[31] ISO, 2004, Road vehicles - Ergonomic aspects of transport information and control systems - Occlusion method to assess visual distraction due to the use of in-vehicle information and communication systems. Committee Draft Standard ISO/CD 16673. ISO/TC 22/SC 13 N 763. 
[32] Green, P., 2002, Motor vehicle driver interfaces. In The Human-Computer Interaction Handbook, Jacko, J.A. \& Sears, A. (Eds.) (UK: Lawrence-Erlbaum Associates, Inc.), pp. 844-860. 
FIGURES

FIGURE 1

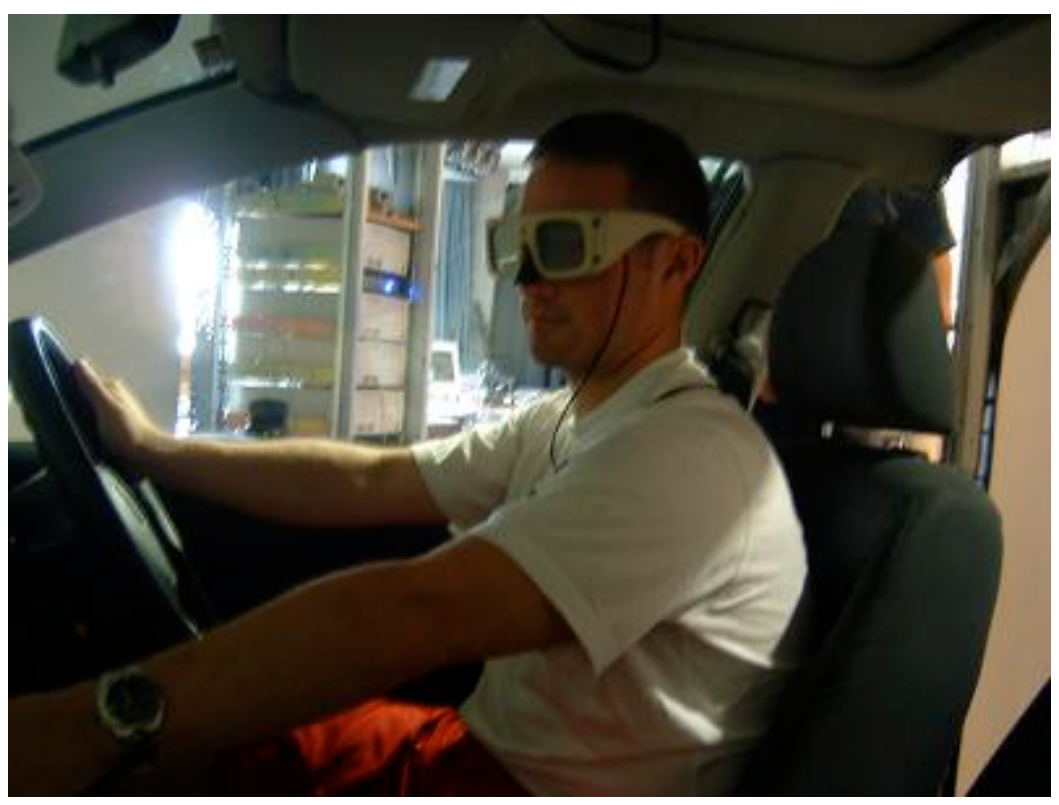

FIGURE 2

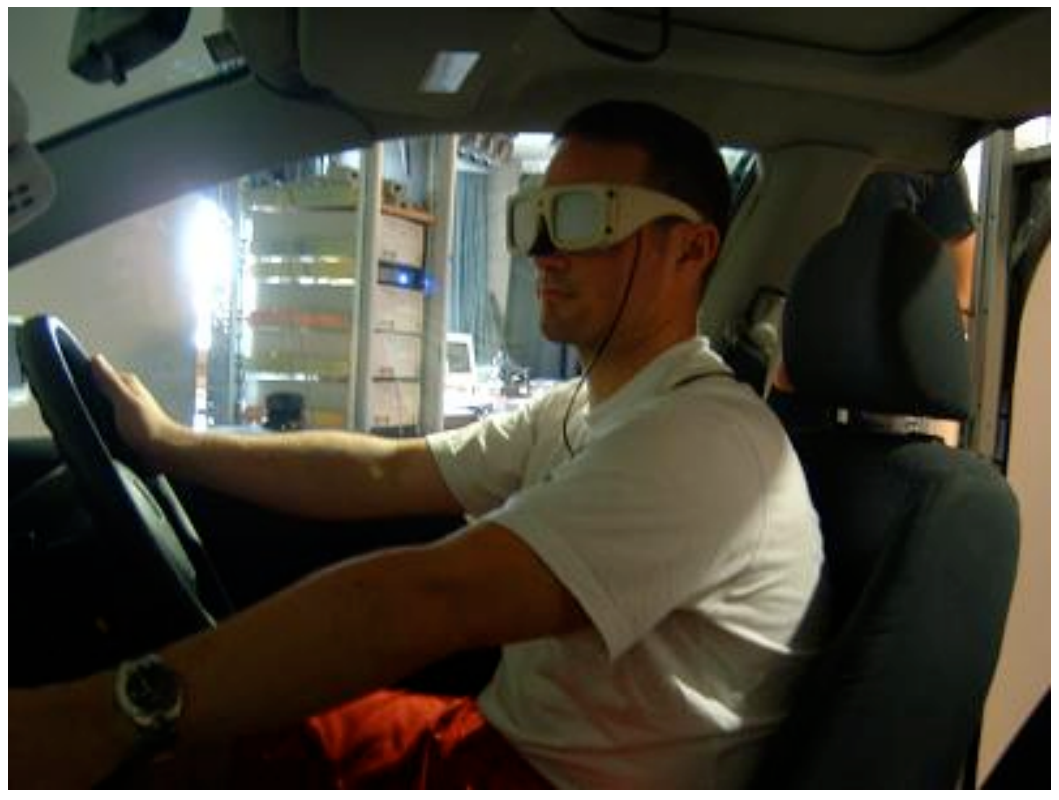


FIGURE 3

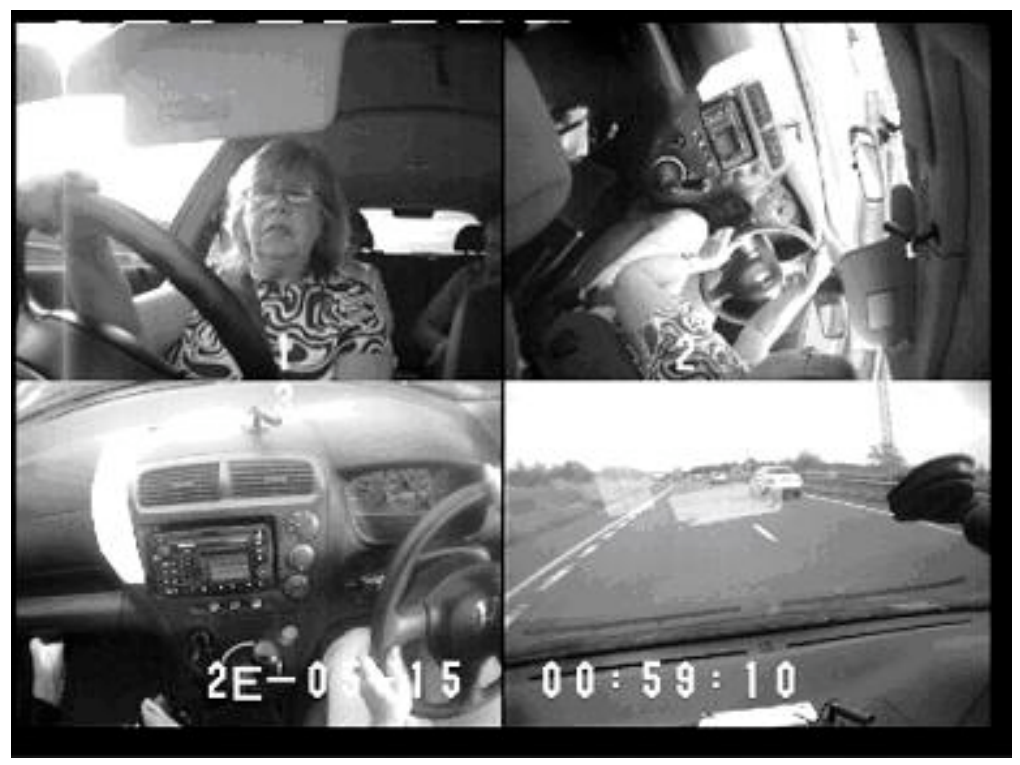




\section{FIGURE CAPTIONS}

Figure 1: Occlusion goggles, shutter open

Figure 2: Occlusion goggles, shutter closed

Figure 3: Camera views 